\title{
Four year experience with the AO Anterior Thoracolumbar Locking Plate
}

\author{
JS Thalgott ${ }^{1,2,3,4}$, MB Kabins ${ }^{1,3}$, M Timlin, K Fritts ${ }^{1,2}$ and JM Giuffre ${ }^{2}$ \\ ${ }^{1}$ Center for Diseases and Surgery of the Spine, 600 South Rancho Drive, Suite 107 Las Vegas, NV 89106-4806, USA; \\ ${ }^{2}$ International Spinal Development and Research Foundation, 500 South Rancho Drive, Suite $8 A$ Las Vegas, NV \\ 89106-4806, USA; ${ }^{3}$ University of Nevada School of Medicine, ${ }^{4}$ University of California, Irvine
}

For decades spinal surgeons have attempted to design simple, single stage anterior internal fixation systems for the thoracic and lumbar spine. Early devices presented both biomechanical and technical problems. The AO Anterior Thoracolumbar Locking Plate (ATLP) was designed to solve some of the problems encountered with early anterior instrumentation. The ATLP system is constructed in Commercially Pure titanium. It is a low profile device indicated for use for unstable burst fractures in the anterior column; metastatic tumor management; and degenerative diseases of the thoracolumbar spine between levels T10 and L5. Implantation of the device involves direct anterior decompression with sagittal reduction and corpectomy. This is followed by grafting reconstruction, and plate fixation. This device has been implanted in 25 patients with an average follow-up of 38 months. There were five (5) broken screws in three (3) patients, and no broken plates. Implant related postoperative complications included two misplaced screws. Preliminary results indicate that the ATLP system seems to be a safe, low profile, MRI/CT compatible device that provides definitive single stage fixation of the anterior spinal column.

Keywords: internal fixation; thoracolumbar spine; AO Anterior Thoracolumbar Locking Plate; anterior column

\section{Introduction}

Anterior instability of the thoracic and lumbar spine, with and without neurological deficit has been a controversial area of management for spinal surgeons for decades. Reliable techniques were developed utilizing posterior instrumentation for unstable fractures in the 1960s with Harrington rods. Harrington instrumentation was biomechanically flawed ${ }^{1-4}$ and had serious rotational instability drawbacks. Subsequent posterior devices were developed including the AO Internal Skeletal Fixator; ${ }^{1,2,6-8}$ and the CotrelDubosset, ${ }^{9-11}$ and the Isola types of $\mathrm{rod} / \mathrm{screw}$ constructs. These devices provided stability for immediate mobilization and powerful reduction and fixation capabilities. Even with these improved devices, posterior instrumentation alone for an anterior column injury was a controversial approach. The inadequacy of posterior instrumentation to solve all spinal instability problems necessitated the development of anterior fixation systems.

Several authors ${ }^{8,12-17}$ have demonstrated the advantages of direct anterior decompression for anterior neural compression in burst fractures as was first popularized by Bohlman in the 1970s. $1,18,19$

Correspondence: JS Thalgott, International Spinal Development and Research Foundation, 500 South Rancho Drive, Suite 8A, Las Vegas, NV 89106-4806, USA
Initially, the corpectomy defect was stabilized with a tricorticate iliac crest graft or fibular strut allograft. Posterior instrumentation or external immobilization was still necessary to provide reliable stability. This caused prior investigators to develop anterior fixation devices to allow definitive single stage decompression and anterior stabilization. ${ }^{7,8,12-15,20,21}$ The early devices such as the AO DCP plate ${ }^{16}$ and the Contoured Anterior Spinal Plate system $^{20}$ lacked reduction capabilities and did not have rigid platescrew interfaces to stop adjacent segments from falling into kyphus. Other systems developed include the Kostuik device, ${ }^{21}$ and the first generation AO plate developed by Yuan. ${ }^{8}$ These devices also lacked a rigid fixed plate-screw interface which could lead to kyphus and screw migration from the plate.

Anterior fixation systems that were more rigid in design were developed by Dunn, ${ }^{22}$ and Kaneda ${ }^{15}$ simultaneously. The Dunn device provided immediate rigid stability of the fracture. However, it was a high profile device that led to reported cases of death caused by aortic erosion. ${ }^{23}$ The Kaneda system also provided rigid stability of the fracture but was too technically demanding.

Another drawback shared by all of these prior devices was that each was manufactured in stainless steel which seriously interferes with postoperative MRI 
and CT images. Also, many patients are allergic to the high content of nickel found in stainless steel. The recently developed Z-plate by Zdeblick, ${ }^{24}$ is a fairly rigid device which is manufactured in titanium. However, the Z-plate is a relatively high profile device and lacks a locking screw/plate interface.

AO stands for Arbeitsgemeinschuff fuer Osteosynthesefragen, or in English, Association for the Study of Internal Fixation. The AO is a non-profit foundation whose primary philosophy is: 'anatomic reduction, stable fixation, atraumatic surgical technique, and early mobilization foregoing external fixation'. The Anterior Thoracolumbar Locking Plate (ATLP, Synthes USA, Paoli, PA) was developed by the AO with this philosophy in mind. The system provides compression and rigid fixation across a bone graft in the anterior thoracolumbar spine and allows for rapid mobilization of the patient in lieu of external fixation. The ATLP is approved by the United States Food and Drug Administration for use between levels T10 and L5. It is inherently low profile, with a smooth, rounded contour (Figure 1). This device can be turned either so that the curve is in lordosis or in kyphosis, depending on which is needed. This implant was designed to be placed anterolaterally. The ATLP system is a rigid fixed angle system which allows a stable sagittal plane reconstruction. The plate design allows for two screw fixation points per anchoring vertebral body. The posterior screw orientation is perpendicular to the plate, thus avoiding spinal canal penetration. The anterior screw orientation is posteriorly directed to give a triangulation effect in the vertebral body which prevents screw 'back-out' (Figure 2). The ATLP system includes a titanium plate in various sizes depending upon anatomical differences, and titanium screws. Four screws are permanently seated in the chosen vertebral bodies at the conclusion of implantation. Two temporary screws are used to hold the plate in place for drilling and seating of the permanent screws; to provide direct compression across the graft; and secure the plate to the spine. A specific set of instruments (AO/ASIF Spinal Instruments for Anterior Surgery) are used to facilitate implantation of this system.

Biomechanically, the system is extremely rigid. This is demonstrated by two common analyses used to test plate rigidity. The system has been tested to dynamic failure at 10,000,000 cycles of a load at approximately 900 newtons. The maximum load before deflection of $15 \mathrm{~nm}$ occurs was approximately 1400 newtons. An anterior device must be able to handle the significant compressive forces of the anterior column. These two tests show that the ATLP system can withstand those forces without failure. The screw removal torque is approximately $5.5 \mathrm{nM}$. This, combined with the advantage of a locking plate/screw interface, ensures the likelihood of screw migration or 'back-out' is reduced significantly compared with previous anterior systems. The mode of failure in an incomplete compressive load cycle is that of plate failure in the vertebrectomy model. However, if the plate is loaded cyclically, completely in distraction and then completely in compression, the mode of failure is screw breakage.

While the ATLP provides rigid fixation, it does not provide reduction capabilities. Reduction must be attained with supplementary instrumentation and grafting prior to inserting the device. Indications for use of the Anterior Thoracolumbar Locking Plate include burst fractures, metastatic tumors, infections, and degenerative diseases of the thoracolumbar spine

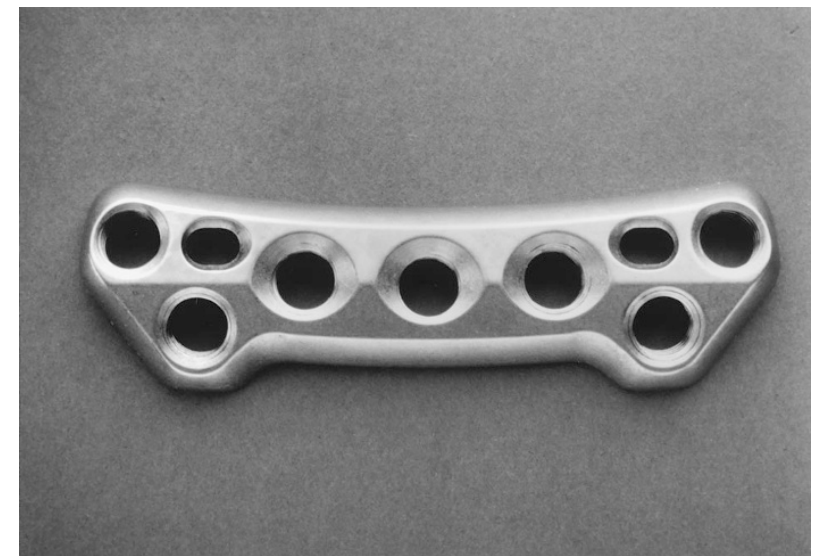

Figure 1 The Anterior Thoracolumbar Locking Plate is curved into lordosis or kyphosis depending on the orientation. It is designed for two screws in each vertebral body and the possibility of intervening segmental fixation. Reprinted from Manual of Internal Fixation of the Spine, Thalgott JS, Aebi M (eds) by permission of the publishers Lippincott-Raven

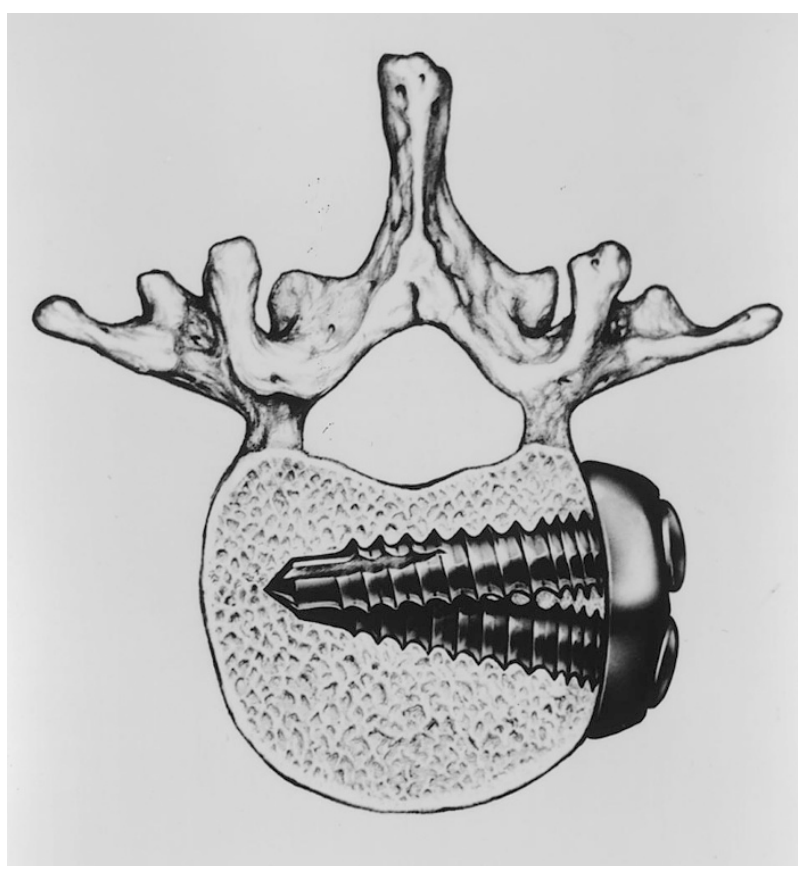

Figure 2 Triangulate-angled screws locked into the plate and shown embedded in the vertebral body 
from levels T10 to L5. The system should not be used in patients with poor bone quality; on vertebral bodies too small to hold the construct; or for the management of unreduced fracture dislocations.

\section{Materials and methods}

Twenty-five (25) patients, 17 female and eight (8) male, were implanted with the ATLP. The average age was 43.8 years with a range of 22 to 81 years. Primary diagnoses included 14 fractures at the thoracolumbar junction; three metastatic tumors; one gun shot wound (which we place in the 'traumatic' group), two disc herniations; one failed laminectomy; one post-traumatic kyphosis; one pseudarthrosis; one spondylolisthesis; and one spondylolysis which we place in the 'nontraumatic' group. Twenty-two (22) patients were nonsmokers at the time of their surgeries. Twenty-three (23) patients had private insurance and 21 patients had had no prior spine surgeries.

There were no neurological deficits presented in the non-traumatic group. However in the traumatic group, two (2) patients presented with complete paraplegia; one (1) patient presented with spinal canal compromise from a retropulsed fracture fragment and partial paraplegia; one (1) patient presented with spinal canal compromise from a metastatic tumor; and three (3) patients presented with myelopathy. There were four (4) single-level and 20 double-level fusions as well as one (1) triple-level fusion. Alternative approaches to the traumatic group were discussed previously. With respect to the eight (8) patients in the non-traumatic group, each had had conservative treatment for at least 6 months, which had failed, prior to the surgery. Other instrumentation such as transpedicular or translaminar fixation may have been used in conjunction with anterior discectomy and fusion. However, it was decided that single stage anterior fixation was the most beneficial treatment for this set of patients. The greatest deformity or vertebral angulation encountered was in the patient with grade II isthmic-lytic spondylolisthesis. In the judgment of the surgeon, patients with a partial or complete neurological deficit were deemed to be in need of immediate stabilization. The technique used for implantation of the ATLP was as follows:

Once the decision for anterior decompression and fixation was made, there were several options for approach. These included a thoraco-abdominal; transthoracic; or retroperitoneal approach. It is the authors' personal bias that a right sided approach is best for thoracolumbar fractures or thoracolumbar pathology. The pathological level was identified followed by a standard corpectomy or discectomy with or without neural decompression. Next, an osteotome was used to square the end plates and make them as parallel as possible. Following this, appropriate sized bone graft or cage was chosen to span the corpectomy site. Choices available to the surgeon included autograft, allograft, or a cage system. Our current preference is the MOSS titanium cage system packed with coral or autologous bone (Table 1). Once the graft was inserted, the appropriate sized plate was chosen, and was placed anterolaterally on the posterior one-quarter of the vertebral bodies. A lateral radiograph was taken to ensure proper positioning. Temporary fixation was achieved using small fragment titanium screws. Temporary fixation was necessary before seating the permanent screws because the torque required to seat the screws is quite high. Temporary holes were drilled to a depth of $40 \mathrm{~mm}$ with a $2.5 \mathrm{~mm}$ drill using a DCP drill guide. The temporary small fragment screws were then placed in a 'double DCP' mode. This was done by putting the screws in loosely and tightening each temporary screw against the other providing additional compression across the graft (Figure 3). Once the temporary fixation and resulting compression of the graft were achieved, the posterior holes were drilled. Dedicated drill guides were

Table 1 Fusion materials used with the ATLP

\begin{tabular}{lc}
\hline Graft & $\begin{array}{c}\text { No. of } \\
\text { patients }\end{array}$ \\
\hline Tricorticate autograft/fibular strut allograft & 7 \\
Fibular strut allograft & 6 \\
MOSS titanium cage/tricoritcate autograft & 5 \\
Polymethylmethacrylate & 2 \\
$\begin{array}{l}\text { Fibular strut allograft/GraftOn demineralized bone } \\
\quad \text { matrix }\end{array}$ & 1 \\
$\begin{array}{l}\text { MOSS titanium cage/polymethylmethacrylate } \\
\text { Fibular strut allograft/GraftOn demineralized bone }\end{array}$ & 1 \\
$\quad$ matrix/Pro Osteon 500 coralline hydroxyapatite & 1 \\
$\begin{array}{l}\text { MOSS titanium cage/tricoritcate autograft/ } \\
\text { GraftOn demineralized bone matrix }\end{array}$ & 1 \\
$\begin{array}{l}\text { MOSS titanium cage/tricorticate autograft/ } \\
\text { GraftOn demineralized bone matrix/Pro Osteon 500 } \\
\quad \text { coralline hydroxyapatite }\end{array}$ & 1 \\
\hline
\end{tabular}

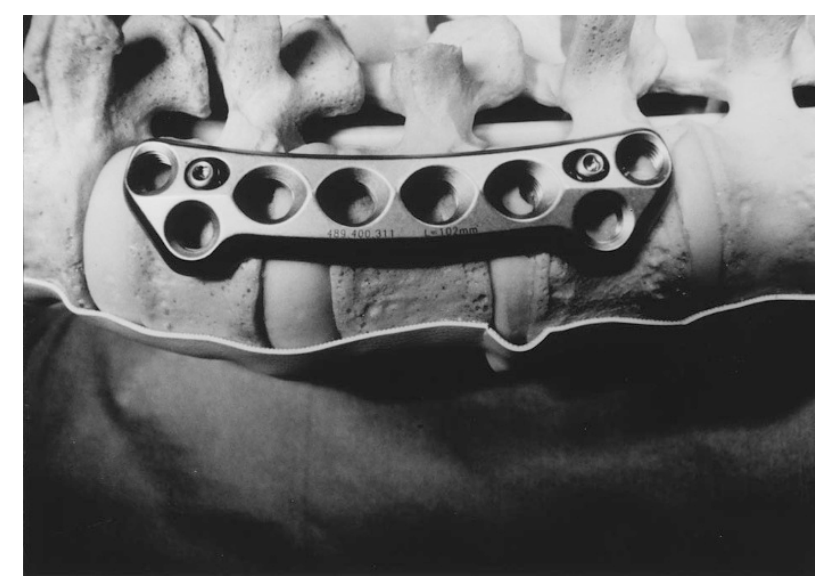

Figure 3 The ATLP after seating the temporary fixation screws on a sawbones model. Reprinted from Manual of Internal Fixation of the Spine, Thalgott JS, Aebi M (eds) by permission of the publishers Lippincott-Raven 
screwed into the posterior holes of the plate to ensure perpendicular placement of the drill relative to the plate (Figure 4). The holes were drilled to a depth of $30-35 \mathrm{~mm}$. The drill bits used have automatic stops to prevent over-drilling. The correct size screws were selected by measuring the depth of the vertebral body and adding $5 \mathrm{~mm}$ for the plate thickness. After drilling the holes, the threaded drill guides were removed and the two $7.5 \mathrm{~mm}$ permanent posterior screws were inserted. The temporary screws were then removed. The threaded drill guides were screwed into the anterior holes; the anterior holes were drilled; and the screws were inserted into the vertebral bodies. All four screws must be completely seated into the plate to secure the locking mechanism of the screw (Figure 5). Interoperative lateral and AP radiographs were taken to ensure proper placement and also to ensure that the screws were entirely contained within the vertebral bodies and did not enter the spinal canal.

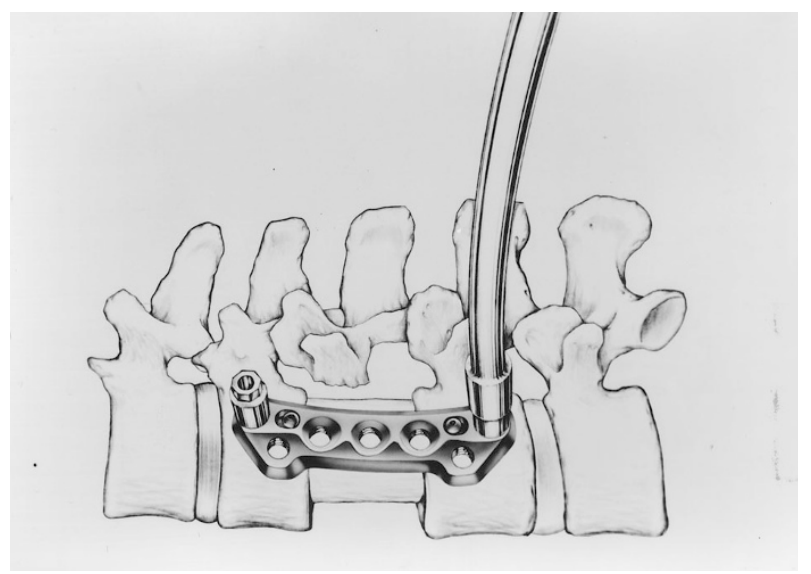

Figure 4 The dedicated drill guides are used to ensure angleperfect placement of the posterior screws

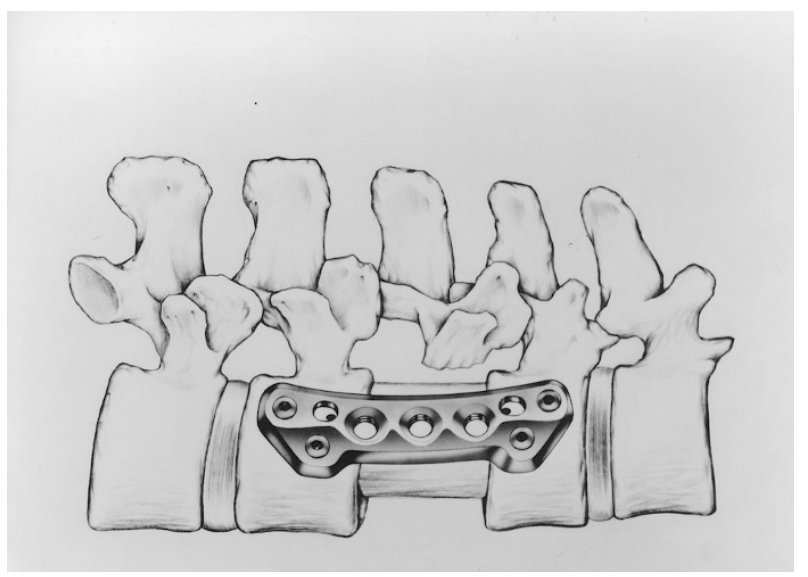

Figure 5 The ATLP with all 4 screws locked into the plate. Reprinted from Manual of Internal Fixation of the Spine, Thalgott JS, Aebi M (eds) by permission of the publishers Lippincott-Raven

\section{Results}

Of the 25 patients implanted with the ATLP system, the average follow-up time for this group was 38 months with a range of 21 to 52 months. The average blood loss was $800 \mathrm{cc}$. There were no complications perioperatively. Postoperatively, 19 patients have fully intact instrumentation. Three (3) patients retained a total of five (5) broken screws; and three (3) patients with metastatic disease have died of complications unrelated to their surgery in the perioperative time frame. No patient in the non-traumatic group had any neurological deterioration. In the traumatic group, one female patient developed difficulty with urinary control. No sexual or bowel complications occurred postoperatively. The three (3) patients presenting with myelopathy improved clinically and continue to do so. The patient who had spinal cord compromise from a retropulsed bone fragment now has minimal back pain and no neurological deficit at 24 months. A male patient who presented with complete paraplegia improved considerably and now walks without assistance of any kind at 24 months postoperatively (Figure 6). The other patient who had complete

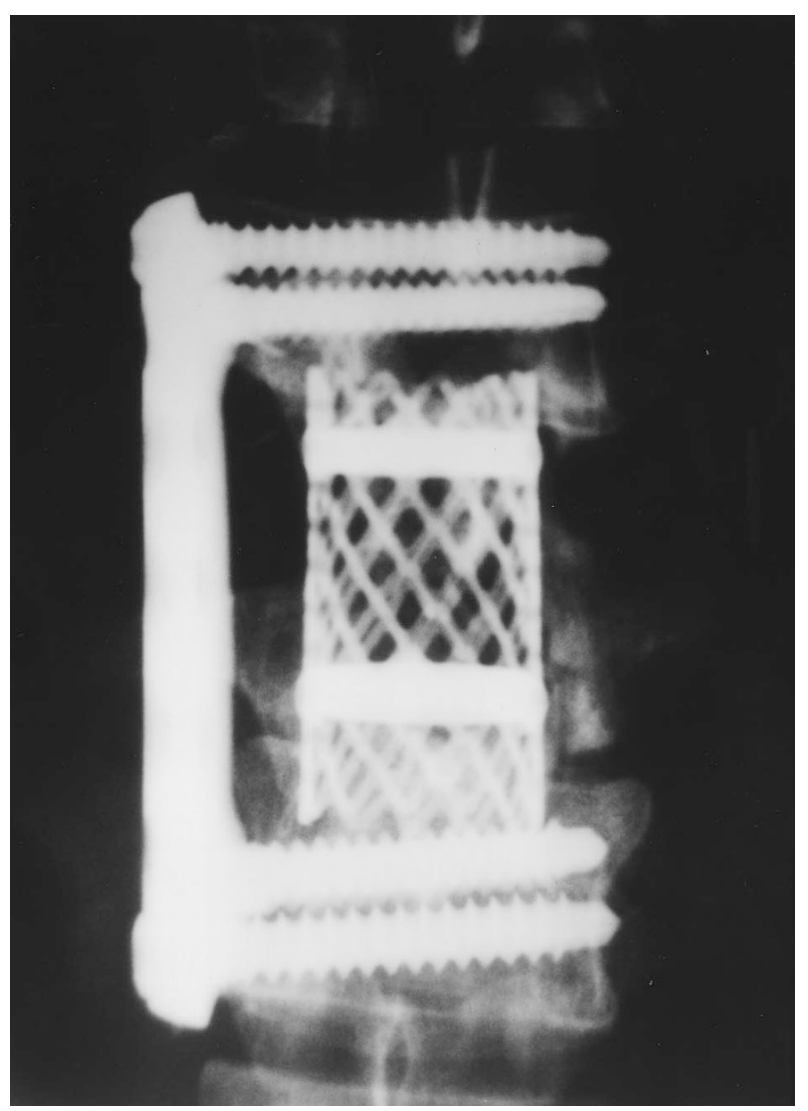

Figure 6 A lateral radiograph at 8 months postop of a 29 year old male patient presenting with complete paraplegia and anterior burst fracture at L2. The patient now walks without assistance 
paraplegia has not improved neurologically, but also has not deteriorated further.

We encountered two postoperative implant complications. In one patient, the plate was too long. Consequently, the screws cut into the endplate and required posterior instrumentation. In another patient, the surgeon became disoriented in the caudal placement of the plate which resulted in violation of the spinal canal by the screw. This was not detected in the intraoperative radiographs but was discovered at follow-up. This did not produce a neurological deficit, but revision with posterior instrumentation was necessary, without sequelae. There was no radiographic evidence of any degree of pseudarthrosis or of resorption of the bone grafts. All of the grafts are either fused or were heavily consolidated, based upon $\mathrm{AP}$ and lateral radiographic evaluation.

\section{Discussion and conclusion}

Of the patients with broken screws: Two had first generation screws which have subsequently been redesigned. The first generation screw had a very short machine thread which led to a stress riser in the

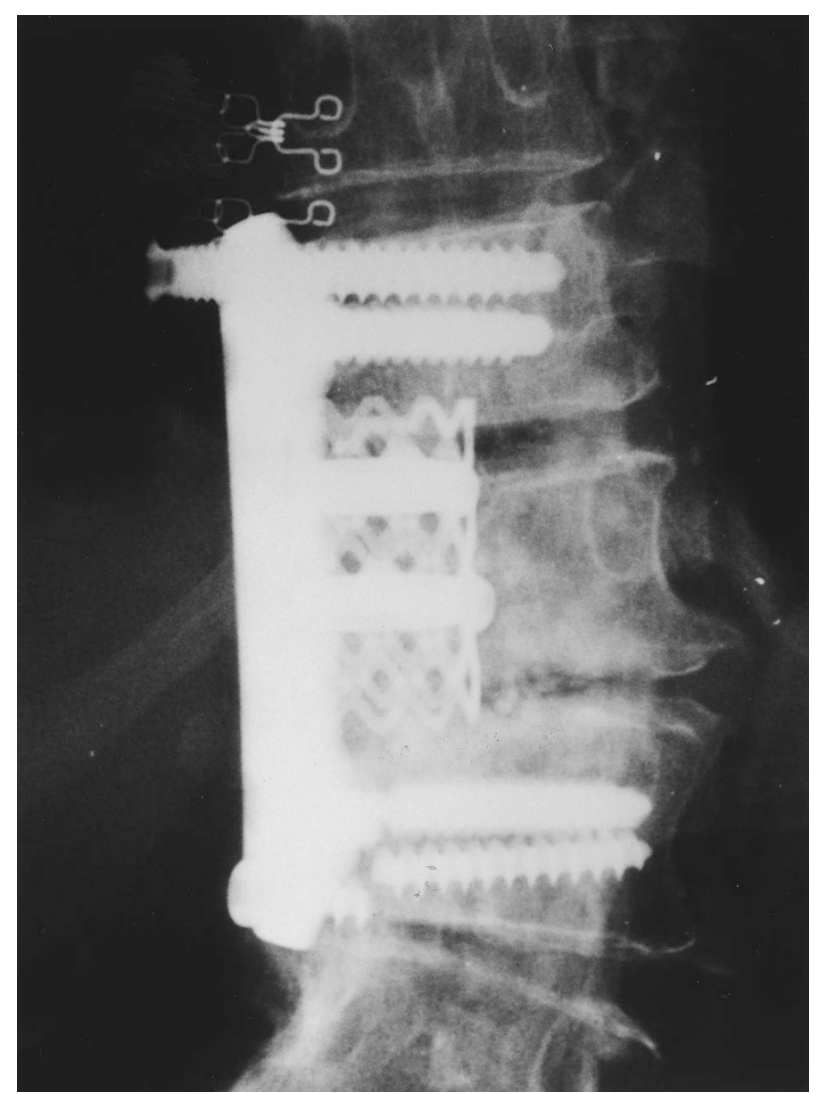

Figure 7 A lateral radiograph at 18 months postop of a 76 year old osteopenic female presenting with pseudarthrosis at T12-L1. Her caudal screws backed out due to her osteopenia and then fractured. Her clinical condition is good with no neurologic deficit and she appears to be solidly fused screw. The machine thread design was lengthened giving a larger cross sectional area at the plate/screw junction. One of these patients lost correction of approximately five degrees but did not require subsequent posterior instrumentation. The third patient, a 65 year old female retained two (2) broken second generation screws. She was severely osteopenic causing the screws to back-out and subsequently fracture at 24 months postoperatively (Figure 7). Her clinical result is good, with no neurological deficit and there appears to be solid fusion. This patient has chosen to refrain from removal of the ATLP.

We feel that after review of the biomechanical studies and our initial clinical experience, this implant proves to be a rather simple, safe device which provides immediate stability after direct anterior spinal decompression for a variety of pathologies. It is also MRI/CT compatible (Figure 8) and allows visualization of the surrounding soft tissues. Anterior fixation technology has evolved over the last two decades with the aim of providing definitive single stage management of anterior pathology. This new implant provides definitive technological advances over conventional anterior systems.

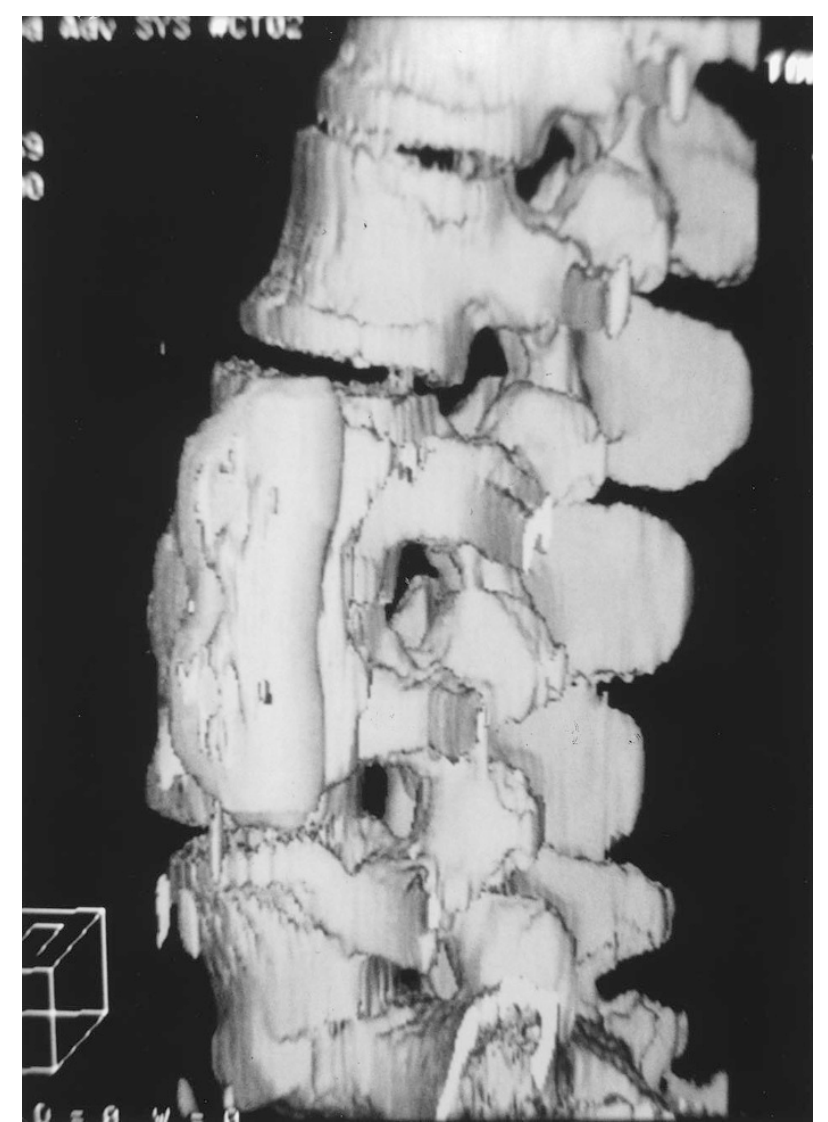

Figure 8 A three-dimensional CT scan showing the compatibility of the ATLP with postoperative testing. Reprinted from Manual of Internal Fixation of the Spine, Thalgott JS, Aebi M (eds) by permission of the publishers Lippincott-Raven 


\section{References}

1 Aebi M, Etter C, Kehl T, Thalgott J. Stabilization of the lower thoracic and lumbar spine with the internal spinal skeletal fixation system. Spine 1987; 12: $544-551$.

2 Aebi M, Mohler J, Zach G, Morscher E. Analysis of 75 operated thoracolumbar fractures and fracture dislocation with and without neurological deficit. Arch Orthop Trauma Surg 1986; 105: $100-112$.

3 Gertzbein SD, Macmichael D, Tile M. Harrington instrumentation as a method of fixation in fractures of the spine. $J$ Bone Joint Surg 1982; 64B 526-529.

4 Phillips DL, Brick GW, Spengler DM. A comparison of Harrington rod fixation with and without segmental wires for unstable thoracolumbar injuries. J Spinal Disord (US) 1988; 1(2): $151-161$.

5 Aebi M, Etter C, Kehl T, Thalgott J. The internal skeletal fixation system: a new treatment of thoracolumbar fractures and other spinal disorders. Clin Orthop 1988; 227: 30-43.

6 Dick W et al. A new device for internal fixation of thoracolumbar and lumbar spine fractures: The 'fixateur interne'. Paraplegia 1985; 23: $225-232$.

7 Kostuik JP, Errico TJ, Gleason TF. Techniques of internal fixation for degenerative conditions of the lumbar spine. Clin Orthop 1986; 203: $219-231$

8 Yuan HA et al. Early clinical experience with the Syracuse IPlate: An anterior spinal fixation device. Spine 1988; 13: 278 285.

9 Engler GL. Cotrel-Dubousset Instrumentation for reduction of fracture dislocations of the spine. Journal of Spinal Disorders 1990; 3(1): $62-66$.

10 Farcy JP, Weidenbaum M. A preliminary review of the use of Cotrel-Dubousset instrumentation for spinal injuries. Bull Hosp Jt Dis Orthop Inst (US): Spring 1988; 48(1): 44-51.

$11 \mathrm{McBride}$ GG. Cotrel-Dubousset rods in spinal fractures. Paraplegia (Scotland), 1989; 27(6): 440 - 449 .

12 Been HD. Anterior decompression and stabilization of thoracolumbar burst fractures by the use of the Slot-Zielke device. Spine 1991; 16(1): 70 - 77.
13 Haas N, Blauth M, Tscherne H. Anterior plating in thoracolumbar spine injuries. Indication, technique, and results. Spine 1991; 16(3 Suppl): S100 - S111.

14 Humphries AW, Hawk WA, Berndt KL. Anterior fusion of the lumbar spine using an internal fixation device. J Bone Joint Surg 1959; 41 A: 371

15 Kaneda K, Abumi K, Fujiya M. Burst fractures with neurologic deficits of the thoracolumbar-lumbar spine. Results of anterior decompression and stabilization with anterior instrumentation. Spine 1984; 9: 788 - 795.

16 McAfee PC, Bohlman HH, Yuan HA. Anterior decompression of traumatic thoracolumbar fractures with incomplete neurological deficit using a retroperitoneal approach. J Bone Joint Surg 1985; 67A: $89-104$

17 McAfee PC, Yuan HA, Lasda N. The unstable burst fracture. Spine 1982; 7: 365-373.

18 Bohlman HH, Freeajfel A, Dejak J. Spinal cord injuries and late anterior decompression of spinal cord injuries. J Bone Joint Surg 1975; 57A: $1025-1031$

19 Bohlman HH, Eismont FJ. Surgical techniques of anterior decompression and fusion for spinal cord injuries. Clin Orthop 1982; 154: $57-67$.

20 Black RC et al. A contoured anterior spinal fixation plate. Clin Orthop 1988; 227: 135-142.

21 Kostuik JP. Anterior spinal cord decompression for lesions of the thoracic and lumbar spine: Techniques, new methods of internal fixation and results. Spine 1983; 8: $512-531$

22 Dunn HK. Anterior stabilization of thoracolumbar injuires. Clin Orthop 1984; 189: $116-124$

23 Jendrisak MD. Spontaneous abdominal aortic rupture from erosion by a lumbar spine fixation device: a case report. Surgery 1986; 99(5): $631-633$.

24 Zdeblick TA. Anterior Thoracolumbar Instrumentation. Joint Section on Disorders of the Spine and Peripheral Nerves. Oral Presentation Feb 1995: Phoenix, AZ, USA. 